\title{
Structure, Properties, and Modification of Polytrifluorochloroethylene: A Review
}

\author{
Jiajia Zou *, Maocheng Zhang, Mengqiu Huang, Dan Zhao and Yinhai Dai \\ China Electronics Technology Group Corporation No. 38 Research Institute, Hefei, China
}

Polytrifluorochloroethylene (PCTFE) is one of the earliest synthesized and commercialized fluoroplastics. It shows ultralow dielectric constant and loss coupled with other excellent properties such as good water vapor permeation resistance, anti-corrosion, light transparency, creep resistance, and so forth, exhibiting great potential to break the bottleneck of the development of high-frequency communication field. Besides, PCTFE-based materials have already played an essential role in some high-tech fields, including chemical, medical, aerospace, and electrical industries. However, in terms of fundamental research, most of the reports concerning the chemical and physical structure of PCTFE came from the last century, but very few in recent years. Herein, the history of the development and the research progress of the structure, properties, and modification of

OPEN ACCESS

Edited by:

Jun-Wei Zha

University of Science and Technology Beijing, China

Reviewed by: Anna Maria Coclite, Graz University of Technology, Austria

Xu Wang,

Sichuan University, China

*Correspondence: Jiajia Zou

87587398@qq.com

Specialty section:

This article was submitted to Polymeric and Composite Materials,

a section of the journal

Frontiers in Materials

Received: 29 November 2021 Accepted: 24 January 2022

Published: 03 March 2022

Citation:

Zou J, Zhang M, Huang M, Zhao D and Dai Y (2022) Structure, Properties, and Modification of

Polytrifluorochloroethylene: A Review.

Front. Mater. 9:824155.

doi: 10.3389/fmats.2022.824155
PCTFE was introduced respectively and finally the perspective was proposed, aiming to provide guidance for the future research and application of PCTFE-based materials.

Keywords: fluoropolymer, polytrifluorochloroethylene (PCTFE), structure and properties, modification, processing

\section{INTRODUCTION}

With the rapid development of high-frequency microwave communication technology, microwave systems are moving toward integration, multi-functionalization, high speed, and low dielectric loss (Wang et al., 2020a). Ultra-large-scale integrated circuits (ICs) with ultrahigh integration, lower power consumption, and higher performance raise more stringent requirements for high-frequency dielectric polymeric materials. Nevertheless, along with the high integration and miniaturization of ICs, mutual interference easily occurs between nearby interconnects, resulting in resistance-capacitance delay and an increase in crosstalk (Zhao and Liu, 2010; Zhang et al., 2021). Therefore, novel polymer materials with controlled dielectric constant and low loss have attracted more and more attention all over the world.

Benefiting from the highly symmetric and closely packed molecular chains, polytetrafluoroethylene (PTFE) possesses ultralow dielectric constant and dielectric loss (Wang et al., 2020b). Therefore, PTFE is widely used as the substrate of multilayered circuit board and adhesive sheet material. Unfortunately, the intrinsic insolubility and infusibility make PTFE unable to be processed with conventional technologies used for thermoplastics (Dhanumalayan and Joshi, 2018; Tomkovic and Hatzikiriakos, 2020). Besides, the creep resistance and dimensional stability are inferior due to the weak interaction between PTFE molecular chains (Dhanumalayan and Joshi, 2018). Hence, PTFE cannot meet the full demand of electronic communication field, which requires high stability and accuracy of signal transmission. Noticeably, replacement of just a single fluorine atom of PTFE with chlorine destroys the symmetry of molecular structure to reduce crystallinity and lower the melting point; hence, polytrifluorochloroethylene (PCTFE) shows satisfying 
TABLE 1 | Properties of PCTFE and PTFE (McKeen, 2015)

\begin{tabular}{|c|c|c|c|}
\hline & Test method & PTFE & PCTFE \\
\hline Melting point, ${ }^{\circ} \mathrm{C}$ & ASTM D4591 & $320-340$ & $210-216$ \\
\hline Melt viscosity, Pa.s & - & $10^{10}-10$ John and Sandra (2005) & $1-10$ \\
\hline Volume resistivity, $\Omega \cdot \mathrm{cm}$ & ASTM D257 & $>10^{18}$ & $>10^{18}$ \\
\hline Dielectric constant, $25^{\circ} \mathrm{C}$ at $10^{3} \mathrm{~Hz}$ & ASTM D150 & $\sim 2.0$ & $\sim 2.5$ \\
\hline Dissipation factor, $25^{\circ} \mathrm{C}$ at $10^{3} \mathrm{~Hz}$ & ASTM D150 & $<0.0001$ & $<0.025$ \\
\hline Dielectric strength, kV/mm & ASTM D149 & 19.7 & 48 \\
\hline Vapor transmission rate, $\mathrm{g} \cdot \mathrm{mm} / \mathrm{m}^{2} \cdot$ day & ASTM F1249 & 0.022 & 0.008 \\
\hline Heat distortion, ${ }^{\circ} \mathrm{C}$ at $0.45 \mathrm{MPa}$ & ASTM D648 & 122 & 126 \\
\hline Coefficient of thermal expansion $\left(\mathrm{cm} / \mathrm{cm} /{ }^{\circ} \mathrm{C} \times 10^{5}\right)$ & ASTM D696 & $12.6-18$ & 7 \\
\hline Solar transmission, \% & ASTM E424 & - & $>90$ \\
\hline Creep resistance & - & Poor & Excellent \\
\hline
\end{tabular}

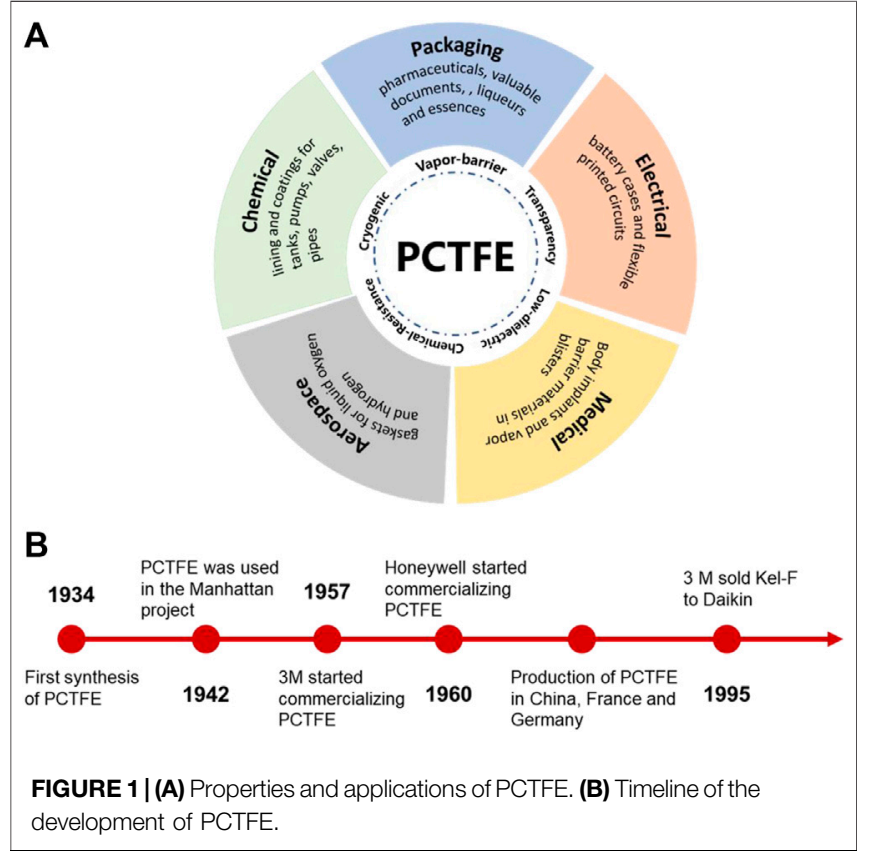

thermoplasticity to be melt processed into products with desired shapes (Teng, 2012; McKeen, 2015). Compared with PTFE, PCTFE not only gains improved creep resistance property, but also shows some additional merits, exemplified by superior vapor-barrier performance and transparency (Boschet and Ameduri, 2014; McKeen, 2015), as illustrated in Table 1 (Boschet and Ameduri, 2014).

PCTFE is one of the earliest developed and commercialized fluoropolymers (Teng, 2012). The primary applications and the timeline of the development of PCTFE are shown in Figure 1. PCTFE was first polymerized in 1934 (Carnevale et al., 2009) and the first patent corresponding with its synthesis was issued by I. G. Farbenindustrie company in 1937. Whereafter, PCTFE was further investigated by the scientists involved in the Manhattan Project for the purpose of uranium isotope separation (Boschet and Ameduri, 2014). In 1942, the USA announced the successful development of PCTFE and put PCTFE into production soon after World War II. In 1957, 3M Company commercialized PCTFE under the Kel-F trademark. In quick succession, other commercially available PCTFE products from Russia, France, Germany, Japan, and China were developed. Currently, the major productivity of PCTFE is contributed by Daikin, Honeywell, and $3 \mathrm{M}$ Company, and it has been widely used in the field of corrosion-resistant pipelines, integrated circuit, and pharmaceutical packaging (Song et al., 2013). For example, Honeywell's blister used for medical packing is a kind of multilayer material integrated with PCTFE, aluminum foil, and another polymer material (John and Sandra, 2005). Nevertheless, in terms of basic research, most of the reports on the analysis of the chemical and physical structure of PCTFE came from the last century, with few reports in recent years. Therefore, in this mini-review, an overview of the research progress on the structure, properties, and modification of PCTFE was presented to provide guidance for its future development and application.

\section{STRUCTURE AND PROPERTIES OF PCTFE}

\section{Structure}

PCTFE is synthesized via radical polymerization of CTFE carrying out either in bulk, suspension (Lazár, 1958), or emulsion (Giannetti, 2001). As shown in Figure 2, the backbone of PCTFE molecule is tightly wrapped by fluorine and chlorine atoms, preventing the carbon skeleton from being exposed. PCTFE is a semicrystalline polymer with variable crystallinity ranging from 40 to $80 \%$. The crystal structure studied by Mencik via X-ray revealed the pseudohexagonal lattice (lattice parameter $\mathrm{a}=\mathrm{b}=0.644 \mathrm{~nm}, \mathrm{c}=4.15$ $\mathrm{nm}, \alpha=\beta=90^{\circ}$ and $\gamma=120^{\circ}$ ) in PCTFE (Mencik, 1973). The main crystal planes are (101) and (102), demonstrating that PCTFE has isotactic sequences. However, the distance of the adjacent $\mathrm{F}$ and $\mathrm{Cl}$ atoms within PCTFE molecular chain is $2.75 \AA$, which is $80 \%$ of the one in isotactic sequences. Accordingly, PCTFE also contains syndiotactic sequences. Price et al. investigated the crystallization rate and crystal morphology of PCTFE when crystallizing at $150-190^{\circ} \mathrm{C}$ (Price, 1952). They found that the crystallization of PCTFE at $175-190^{\circ} \mathrm{C}$ was predominated by heterogeneous nucleation, while the crystallization process at $150-175^{\circ} \mathrm{C}$ was dominated by the combination of homogeneous and heterogeneous nucleation. Meanwhile, the 


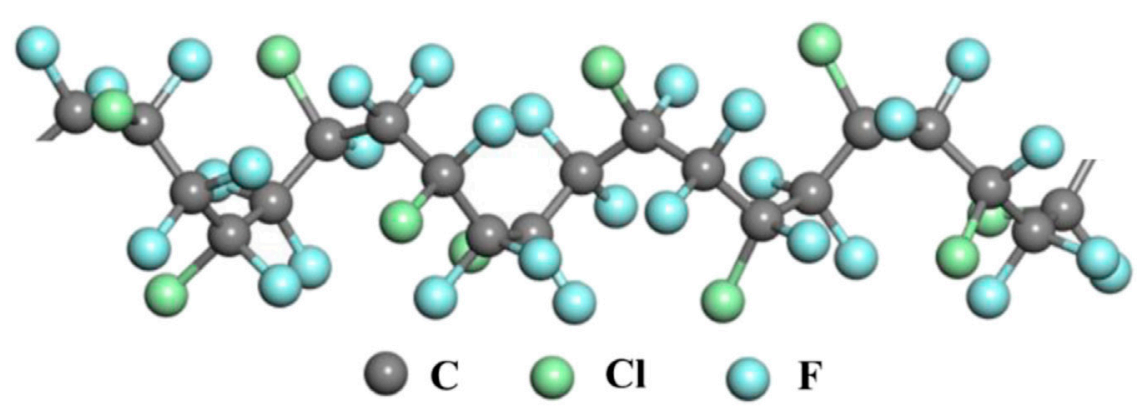

FIGURE 2 | Molecular structure of PCTFE.

influence of molecular weight on the crystallization rate was mentioned as well. According to the investigation of crystallization kinetics, the crystal growth of PCTFE is like that of polyethylene spherulites, which consist of folded-chain crystallites (Hoffman and Weeks, 1962). Furthermore, Hoffman et al. (1966) studied the process and mechanism of PCTFE segmental relaxation under different temperature conditions. By calculating the relaxation time and energy barrier required to reach the equilibrium state of the arrangement of chain segments, and comparing the real relaxation time and activation energy, they proposed that there were at least three kinds of a relaxation in the crystalline phases of PCTFE, i.e., 1) coupling flips of chains within crystals, 2) axis rotation of short molecular chains, and 3) small rotations of chains within crystals and tiny motions of folds on the rough surface of folded-chain crystals. By means of ${ }^{19} \mathrm{~F}$ solid-state NMR spectroscopy, Tatsuno et al. (2007) found that drastic molecular motions occurred within crystalline domains above $120^{\circ} \mathrm{C}$, which was far below the melt temperature of PCTFE. They concluded that PCTFE crystallites are more mobile than those of other semicrystalline fluorinated polymers, such as polyvinylidene fluoride, suggesting the presence of structural imperfections in the PCTFE.

\section{Physical Properties}

The high content of fluorine and chlorine endows PCTFE with outstanding chemical corrosion resistance and chemical inertness. PCTFE is only corroded by molten alkali metal or chlorosulfonic acid at high temperature. Besides, due to the strong electronegativity of fluorine element and low polarizability of $\mathrm{C}-\mathrm{F}$ bonds, PCTFE exhibits extremely low dielectric constant and loss. Moreover, in comparison of PTFE, PCTFE is less symmetric because of the existence of chlorine atoms; hence, the transparency, processability, and creep-resistance properties of PCTFE are much better than those of PTFE (Ma and Li, 2005).

\section{Thermal Properties}

PCTFE, with a glass transition temperature of $71-99^{\circ} \mathrm{C}$ (Khanna and Kumar, 1991) and a melting point of $211-216^{\circ} \mathrm{C}$, is thermally stable up to $250^{\circ} \mathrm{C}$ (Boschet and Ameduri, 2014). When the temperature exceeds $310^{\circ} \mathrm{C}$, PCTFE starts to decompose into $-\mathrm{C}(\mathrm{O})-\mathrm{F}$ at the existence of $\mathrm{O}_{2}$, while the decomposition products include $-\mathrm{CF}=\mathrm{CF}_{2}, \mathrm{CF}_{2}=\mathrm{CFCl}$, and $\mathrm{CF}_{2}=\mathrm{CCl}_{2}$ in a nitrogen atmosphere (Zulfiqar et al., 1996). Zulfiqar et al. (1994) studied the pyrolysis of PCTFE and found that PCTFE decomposed into CTFE monomer, which was derived by the endchain radicals originated from a $\mathrm{C}-\mathrm{C}$ bond cleavage. At the same time, intramolecular chlorine atom transfer occurred, that is, the end-chain radicals grabbed the chlorine atoms from other sequences, resulting in chain fracture, degradation, and transfer reaction. In addition, as a cryogenic polymer, PCTFE shows superior low-temperature toughness and residence to creep in liquid nitrogen, liquid oxygen, and liquefied natural gas (Ma and Li, 2005). Therefore, it is widely used as a liner of liquid natural gas, liquid oxygen, and liquid nitrogen transportation pipeline, liquid fuel seals, and cryogenic valves.

\section{Mechanical Properties}

Replacing a fluorine atom in PTFE by a chlorine atom improves the mechanical properties, involving tensile strength, compression strength, and residence to creep (Teng, 2012). The mechanical properties of PCTFE can be tailored by controlling its crystallinity and molecular weight. For example, PCTFE with high degree of crystallinity is brittle, accompanied by deteriorative impact strength and elongation at break, while the one at lower crystallinity shows better toughness. Brown et al. (2006) investigated the tensile and compression response of PCTFE at various temperatures and strain rate conditions, and they found that the tensile and compression recovery had obvious asymmetry, and the strain-stress response of PCTFE was strongly dependent on temperature and strain rate (shown in Figure 3). When the temperature was above $\mathrm{T}_{\mathrm{g}}$, the mechanical toughness of PCTFE was significantly improved. Zhang and Zhou (2017) found that the hardness and elastic recovery ratio of PCTFE samples were increased with the decrease of temperature, but the compression ratio turned to be decreased. More significantly, the samples were demonstrated to be capable of maintaining good sealing performances at low temperature.

\section{Dielectric Properties}

Another highly desirable characteristic of PCTFE is the ultralow dielectric constant and loss in broadband, which were almost unaffected by temperature or humidity, making PCTFE an excellent choice for the material used for high-frequency communication. The dielectric properties of low molecular weight PCTFE were studied by Hara and his cooperators 



FIGURE 3 | The effect of strain rate on the $\mathbf{( A )}$ compressive response and $\mathbf{( B )}$ tensile response of PCTFE at $23^{\circ} \mathrm{C}$, and the effect of temperature on the $(\mathbf{C})$ compressive response and (D) tensile response of PCTFE at $10^{-3} \mathrm{~s}^{-1}$ (Brown et al., 2006).

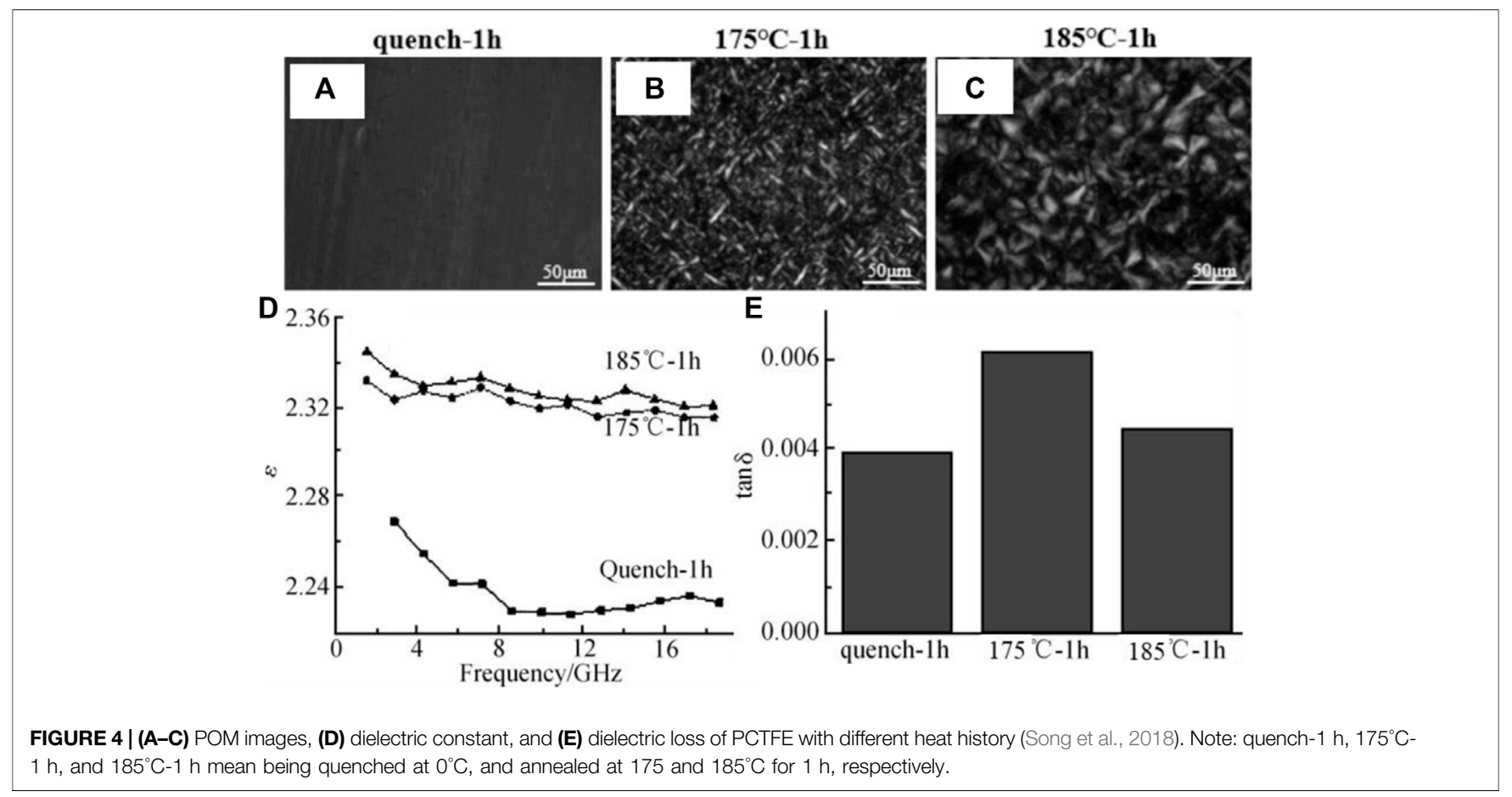

(Hara, 1967). They proposed that the crystalline regions contributed to the polarization, which arises from two dielectric polarizable modes in the crystalline phase: the main chain dipoles and the end group dipoles. Scott et al. (1962) studied the dielectric relaxation effects of PCTFE in a low- frequency range. They found that the highly crystalline PCTFE exhibited three distinct loss peaks at about $-40,95$, and $150^{\circ} \mathrm{C}$, corresponding to the loss of the lamellar surface, the chain segment motions in the amorphous phase, and the recombination of imperfections inside the crystalline region, 



FIGURE 5| Comparison of PCTFE with perfluoropolymers (PFPs) and other polymers for (A) $\mathrm{He} / \mathrm{H}_{2},(\mathbf{B}) \mathrm{He} / \mathrm{CO}_{2}$, and (C) $\mathrm{He} / \mathrm{CH}_{4}$ separation at $35^{\circ} \mathrm{C}$ in Robeson's plots (Yavari et al., 2018).

respectively. Song et al. (2018) found that there was a great influence of crystalline structure on the dielectric properties of PCTFE. The PCTFE sample with lower crystallinity and crystal size possessed lower dielectric constant and loss, fulfilling the stringent requirement of high-frequency communication, as demonstrated in Figure 4.

\section{Separation/Barrier Properties}

Yavari et al. (2018) discovered that the unexpectedly superior $\mathrm{He} /$ gas separation properties of PCTFE was derived from the combination of $\mathrm{F}$ and $\mathrm{Cl}$ atoms. On the one hand, the $\mathrm{F}$ substituents lead to unexpectedly high $\mathrm{He}$ solubility and exhibit unfavorable interactions with $\mathrm{H}_{2}$ and $\mathrm{CH}_{4}$. On the other hand, $\mathrm{Cl}$ substituents increase solubility parameter and size-sieving ability, yielding high $\mathrm{He} /$ gas diffusivity selectivity. Figure 5 demonstrates the excellent performance of PCTFE for the separation of $\mathrm{He} / \mathrm{H}_{2}, \mathrm{He} / \mathrm{CO}_{2}$, and $\mathrm{He} / \mathrm{CH}_{4}$ in Robeson's plots. Hence, we can easily separate $\mathrm{He}$ from the mixture of $\mathrm{H}_{2}$ and $\mathrm{CH}_{4}$ with the aid of PCTFE. More noticeably, as the best vapor-barrier polymer, PCTFE exhibits ultralow water vapor transmission rate of $0.171 \mathrm{~kg} /\left(\mathrm{m}^{2} \cdot \mathrm{h}\right.$ ) (Xu et al., 2020). In addition, thanks to the high content of $\mathrm{F}$ element, PCTFE is intrinsically inert to acids, bases, and oxides. As an ideal choice for transparent packaging material, PCTFE has low absorption of infrared and ultraviolet light, as well as a high light transmittance $(\sim 90 \%)$.

\section{MODIFICATIONS OF PCTFE}

It must be noted, however, that in spite of the many interesting high-tech applications for PCTFE such as cryogenic components, valves, seals, gaskets, gas barrier films, and energy-related applications, PCTFE also exhibits some disadvantages (Boschet and Ameduri, 2014). First, PCTFE is only soluble in a few hypertoxic organic solvents at high temperature (above $100^{\circ} \mathrm{C}$ ); hence, it cannot be processed through solvent method. Besides, PCTFE has a high melting temperature $\left(\mathrm{T}_{\mathrm{m}}\right)$ and melt viscosity, coupled with a nearby similar decomposition temperature with $\mathrm{T}_{\mathrm{m}}$, making the melt processing of PCTFE rather difficult and costly. Moreover, high crystallization rate accompanied with high degree of crystallinity results in inferior toughness of PCTFE, restricting its further development. Noticeably, the modification of polymers is a common method to optimize their performances and broaden their application fields. Up to now, the modification of PCTFE mainly focuses on three aspects: copolymerization, blending, and surface modification. 

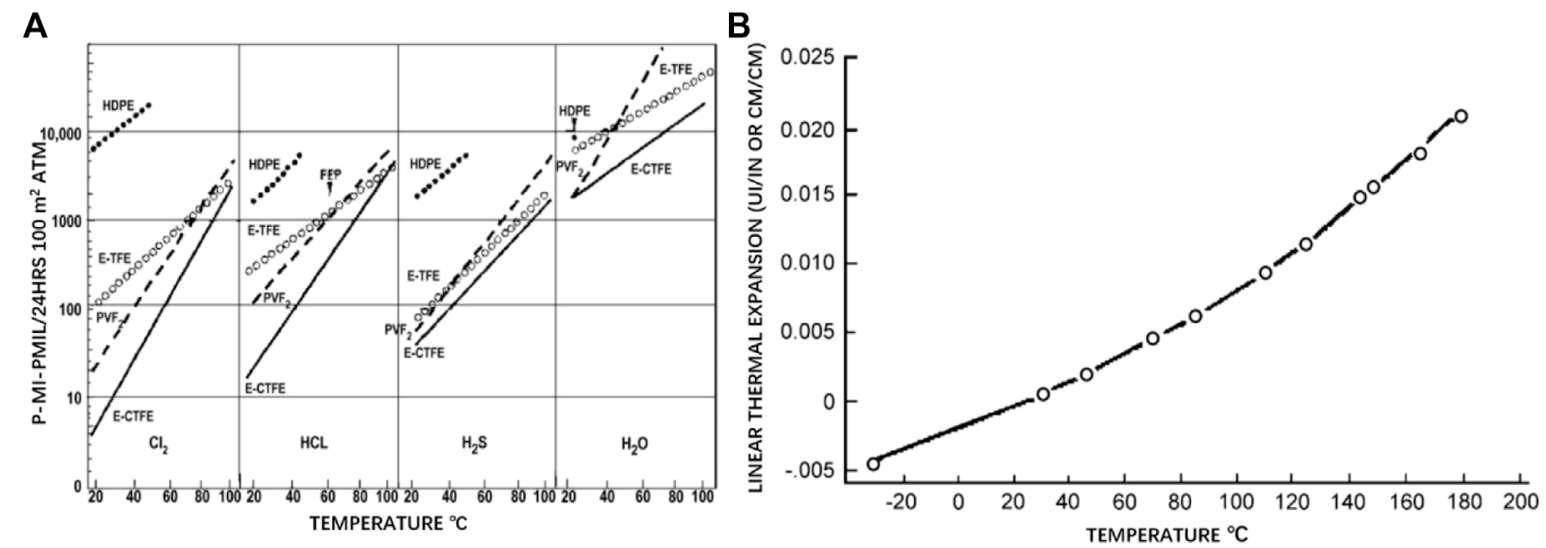

FIGURE 6 | (A) Permeability of ECTFE in comparison with other polymers, (B) linear thermal expansion of ECTFE (Vecellio, 2000).

A

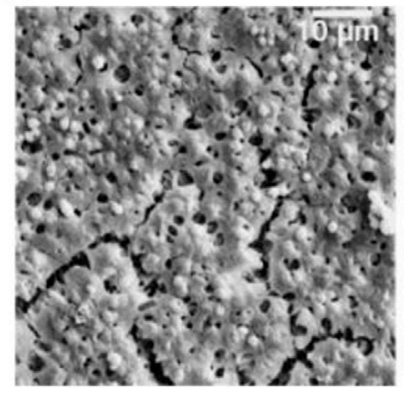

B



C

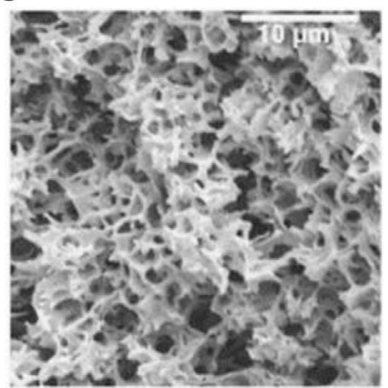

FIGURE 7 | Representative SEM images of quenched surface (A) and cross-section views [(B): low magnification and (C): high magnification] of an ECTFE membrane cast from a 16.5 wt.\% ECTFE solution onto a $150^{\circ} \mathrm{C}$ casting block containing a thin film of DPB (Ramaswamy et al., 2002 ).

\section{Copolymerization Modification}

CTFE can be copolymerized with other monomers to get the copolymers with better performances than PCTFE. Many comonomers have been involved in the copolymerization with CTFE, and the copolymerization process can be divided into two categories: conventional radical copolymerization and controlled radical copolymerization (Boschet and Ameduri, 2014). Until now, the most investigated copolymers of CTFE include poly (CTFE-co-ethylene) (ECTFE) (Reimschuesel et al., 1988), poly (CTFE-co-vinylidene fluoride) (Ameduri, 2009) (P (VDF-co-CTFE), poly (CTFE-co-propylene) (Ishigure et al., 1973), poly (CTFE-co-isobutylene) (Ishigure et al., 1970; Tabata et al., 1970), poly (CTFE-co-acrylates) (Thomas and O'Shaughnessy, 1953), or poly (CTFE-alt-vinyl ether) (Reddy et al., 2011; Koti Reddy et al., 2012).

ECTFE was first synthesized by DuPont Company in 1946, but was commercialized first by Honeywell in 1974. It was reported that the commercialized ECTFE contained a 1:1 M ratio of CTFE and ethylene (Vecellio, 2000). Industrially, ECTFE is produced by aqueous free radical suspension polymerization. Meanwhile, to regulate melting point and ensure improved comprehensive properties of ECTFE, a small amount of the third monomer such as hexafluoroisobutylene or perfluorohexyl ethylene is added (Reimschuesel et al., 1988). Benefiting from the highly alternating structure, ECTFE exhibits similarly good thermal stability, weatherability, and chemical resistance as well as improved processability compared with PCTFE (Wang et al., 2007). Besides, ECTFE has higher resistance to the permeation of the chlorine and the lower coefficient of thermal expansion than other fluoropolymers; the corresponding values can be seen in Figure 6 (Vecellio, 2000). In the aspect of electrical properties, ECTFE has a low dielectric constant, ranging from 2.5 to 2.6, making ECTFE an ideal material used for communication equipment. At present, ECTFE is available in various types of plates, fibers, sheets, and coatings by means of conventional processing methods, including extrusion, injection, and rotational molding. The products of ECTFE have been widely used in the fields of photovoltaic cells and the transportation of industrial chemicals. On the other side, Ramaswamy et al. (2002) successfully prepared microporous ECTFE membranes via thermally induced phase separation (TIPS) method when dibutyl phthalate was chosen as a diluent. The microstructure of the prepared membrane can be seen in Figure 7. It was reported that the membranes with a pore size of $0.1-0.5 \mu \mathrm{m}$ 


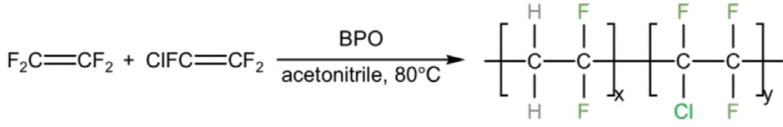

$$
\begin{aligned}
& \text { P(VDF-CTFE) }
\end{aligned}
$$

FIGURE 8 | Preparation of P(CTFE-co-VDF) copolymers by radical copolymerization of VDF and CTFE (Ameduri, 2009).

reached the requirement of microfiltration. Similarly, Xu et al. (2019) adopted acetyl tributyl citrate as diluent to prepare microporous ECTFE membrane via TIPS. The flux of water permeation with $22.4 \mathrm{~L} /\left(\mathrm{m}^{2} . \mathrm{h}\right)$ and the ratio of salt rejection with $99.9 \%$ were achieved, making the prepared membrane a desirable candidate used as the vacuum membrane distillation. Besides, some other diluents such as glycerol triacetate (Karkhanechi et al., 2016), di-ethyl adipate (Ursino et al., 2016), and $N$-methyl pyrrolidone (Simone et al., 2012) are also popular in producing microporous membranes.

Copolymers based on the random copolymerization of CTFE and vinylidene fluoride (VDF) ( $\mathrm{P}(\mathrm{CTFE}-\mathrm{CO}-\mathrm{VDF})$ ) with the chemical structure of $\left[\left(\mathrm{CF}_{2} \mathrm{CFCl}\right)_{\mathrm{x}}\left(\mathrm{CH}_{2} \mathrm{CF}_{2}\right)_{\mathrm{y}}\right]_{\mathrm{n}}$ were first synthesized in 1955 (the simplified preparation process can be seen in Figure 8) and commercialized by the Kellogg Company (Ameduri, 2009). Noticeably, the amount of VDF is crucial in determining the performances of $\mathrm{P}(\mathrm{CTFE}-\mathrm{co}-\mathrm{VDF})$ copolymers. For example, $\mathrm{P}$ (CTFE-co-VDF) copolymers that contain only a small amount of VDF are semicrystalline, thereby remaining thermoplastic. To be specific, the introduction of VDF destroys the regularity of polymer chains to endow $\mathrm{P}(\mathrm{CTFE}-\mathrm{Co}-\mathrm{VDF})$ with lower degree of crystallinity and melting point than PCTFE. On the other hand, those containing $30-75 \mathrm{~mol} \%$ VDF display an amorphous state and exhibit the characteristic of elastomers. These copolymers have excellent thermal stability, anti-oil, chemical resistance, and radiation resistance performances, and can be cross-linked by cross-linking agents such as diamine, diphenol, or peroxide. Usually, we can classify the $\mathrm{P}(\mathrm{CTFE}-\mathrm{co}-\mathrm{VDF})$ copolymers according to their composition. For example, $\mathrm{F}_{2311}, \mathrm{~F}_{2313}$, and $\mathrm{F}_{2314}$ are the random copolymers with the molar ratios of 1:1, 1:3, and 1:4 of VDF and CTFE, respectively (Shu et al., 1986; Gee et al., 2001). Among these, $\mathrm{F}_{2311}$, which can be prepared by vulcanizing, is a translucent elastomer with good weatherability. $\mathrm{F}_{2313}$ is slowly crystallized and has a crystallinity ranging from 10 to $20 \%$. In addition, the initial decomposition temperature of $\mathrm{F}_{2313}$ exceeds $300^{\circ} \mathrm{C}$, showing good thermal stability. $\mathrm{F}_{2314}$ is a crystalline random copolymer with outstanding cryogenic properties and excellent electrical insulation and bonding properties.

PEVE fluorocarbon resins are alternating copolymers of CTFE and vinyl ethers (ethyl-vinyl ether, cyclohexyl vinyl ether, and hydroxybutyl vinyl ether) with a molar ratio of 1:1 (Boutevin et al., 1992). The corresponding synthesis mechanism and molecular structure can be exemplified by the synthesis and molecular simulation of the copolymers of CTFE and ethylvinyl ethers, as illustrated in Figure 9 (Carnevale et al., 2009). In comparison with those in PCTFE, the CTFE units provide FEVE with weatherability, while vinyl ether units lower the crystallization and endow the copolymers with good solubility, glossiness, and flexibility (Sun et al., 2019). It is worth noting that PEVE can be dissolved in either aromatics, esters, or ketones. Hence, one of the most relevant applications, by far, of FEVE copolymers is in paints and coatings. In contrast to PTFE and PVDF, FEVE paints can be cured to protection film at room temperature by adding curing agents, without experiencing hightemperature process. Therefore, FEVE copolymers are widely applied in the fields of engineering, building, new energy, and so on. Recently, to eliminate the negative effects of toxic organic solvent on environment, water-based FEVE fluorocarbon resins become the hotspots. As disclosed in the patent published by



FIGURE 9 | (A) Simplified synthesis mechanism and (B) molecular structure of the copolymers of CTFE and ethyl-vinyl ethers (Carnevale et al., 2009). 
Kawakami et al. (1996), the preparation of water-based PEVE emulsion can be achieved by the introduction of hydrophilic vinyl ethers during the synthesis of PEVE.

\section{Blending Modification}

Blending modification is a convenient and efficient method to improve the macroscopic properties of polymers via physical compounding. For example, Feng et al. (2014) improved the poor stability of PCTFE during processing by adding rare earth stabilizer. They found that the dynamic thermal stability of PCTFE was significantly improved with the increase of stabilizer amount. When the $6 \mathrm{phr}$ stabilizer was added, the synchronous improvement of mechanical toughness and processability was achieved. According to the patent published by $\mathrm{Wu}$ et al. (2015), the addition of nucleating agents offered another method to modify the mechanical and processing performances of PCTFE. Besides, Shen et al. (2021a), Feng et al. (2015), and Li et al. (2015) toughened PCTFE by melt blending it with core-shell acrylate copolymer (ACR) or CTFE copolymers, the mechanism of which was ascribed to the decreased crystal size and the crystallinity due to the strengthened interfacial compatibility. Recently, Shen and his colleagues from Sichuan University proposed a strategy of molecular relaxation by compounding PCTFE with different molecular weight and functional groups via melt blending (Shen et al., 2021b). Benefiting from the broad relaxation distribution and perfect molecular compatibility, the asprepared PCTFE material achieved good mechanical toughness, high light transmittance, low dielectric loss, and water vapor permeability.

Excepting the toughening of PCTFE, the reinforcing modification of PCTFE was investigated as well. Wei and Shi (1995) added carbon fibers (CFs) into PCTFE and studied the impacts of the CF content and length on the mechanical performances of the composites. It was displayed that the tensile and bending strength rose up first and then turned to decline with increasing CF content. In addition, the CF with a length less than $5 \mathrm{~mm}$ exhibited better reinforcing effect. Wen et al. (2018) prepared CF reinforced PCTFE composites by applying extrusioncompression method. It is found that PCTFE melt was less decomposed when using a short screw extruder coupled with low extruding rate, leading to obviously improved compressive strength and compressive modulus.

In addition, Mabry et al. (2007) introduced a kind of fluorinated polyhedral oligomeric silsesquioxane (POSS) into PCTFE and demonstrated that this filler endows the composite material with excellent hydrophobicity. The water contact angle was even larger than that of neat PCTFE. The integration of POSS also lowered the equilibrium torque during extruding. More significantly, the improvement of processability did not sacrifice the thermal stability and mechanical properties of PCTFE.

\section{Surface Modification}

In some specific application fields, PCTFE would be compounded with other materials to make good for its deficiency and improve comprehensive performances. To this end, enough adhesiveness of PCTFE to other materials is required. However, because of low surface energy, PCTFE material commonly needs surface modification to reduce its interface tension with the attached materials. In comparison with other fluoroplastics, PCTFE owns unique reactive activity due to the existence of chlorine atoms. Hence, reactive functional groups can be introduced to PCTFE through nucleophilic substitution and elimination reaction. As reported by Dias et al., carboxylic acid, aldehyde, and alcohol functionalities were independently introduced on the surface of PCTFE via a particular modification process, where lithium reagents containing protected functional groups reacted with polymer film surfaces through a series of selective reduction, addition, and elimination reactions, as illustrated in Figure $\mathbf{1 0}$ (Dias and McCarthy, 1987). Siergiej and Danielson (1983) obtained phenyl-modified PCTFE by controlling the reaction between PCTFE and phenyllithium in helium atmosphere. The results of IR and EDS confirmed that the chlorine atoms in PCTFE are substituted by phenyl groups. Moreover, Okubo et al. (2008) conducted a surface modification by utilizing nonthermal plasma grafting polymerization technology at atmospheric pressure. The results showed that the water contact angle of the modified film was decreased from 91 to $42^{\circ}$. In the T-type peel test, the peel strength between the modified PCTFE film and aluminum foil reached up to $13.3 \mathrm{~N} \cdot \mathrm{mm}$.

\section{HEALTH, SAFETY, AND RECYCLING}

In contrast to the toxic CTFE, PCTFE has low toxicity and almost no toxicological activity under normal conditions. It is physiologically inert and has been approved by the Food \& Drug Administration for use in contact with food or for human implants (Boschet and Ameduri, 2014). PCTFE is a partially fluorinated thermoplastic. The preferred methods for disposing PCTFE-based materials are recycling and reusing them (Drobny, 2020). Generally, the clean, unfilled, and unpigmented scrap materials from the manufacturing and processing of PCTFE can be recycled back into raw material to be reused in applications where the quality requirements are much lower (Ameduri and Sawada, 2016). However, only small portions of PCTFE waste can be recycled in this way. Noticeably, the pyrolysis of PCTFE is accompanied by the generation of some toxic compounds. Consequently, incineration can be used only when the incinerator is equipped by a scrubber for removing hydrogen fluoride, hydrogen chloride, or other acidic products of combustion. If there is no valid recycling or incineration, landfilling of PCTFE waste is justified because it is environmentally stable and contains no harmful substances.

\section{APPLICATIONS AND PERSPECTIVES}

PCTFE are widely used in the manufacture of engineering plates, bars, pipes, corrosion-resistant pumps, and valves. It can also be processed as suspensions for the purpose of corrosion protection, electrical insulation, and achieving film products. It needs to be admitted that PCTFE tended to be replaced by other fluoropolymers in the field of anti-corrosion due to the 


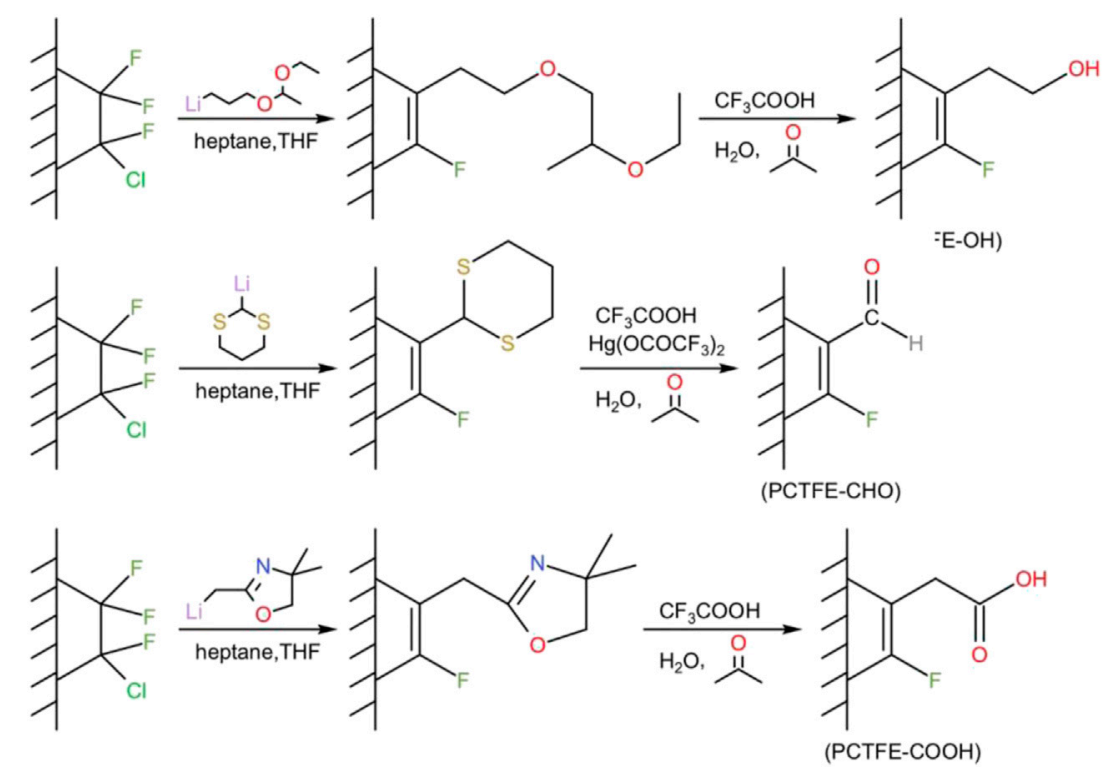

FIGURE 10 | The reactions used to introduce (A) hydroxyl, (B) formyl, and (C) carboxylic groups onto the surface of PCTFE (Mabry et al., 2007).

influence of its price and processing issues. Therefore, the current commercialized products primarily dropped in the field of highend films, accounting for about $75 \%$ of the market share. Up to now, the commercialized PCTFE films possess various trade names, including Neoflon (Daikin, Japan), Aclon (Honeywell, USA), and Aclar, which are mainly used in packaging, bonding, sealing, and other areas (Gardiner, 2015). Nevertheless, PCTFE has some unavoidable limitations. First, it is insoluble in most common organic solvents unless heated above $100^{\circ} \mathrm{C}$, restraining the solution processing of PCTFE. In addition, the borderline thermal stability of the PCTFE melt cannot tolerate sufficiently high processing temperatures. Degradation of PCTFE produces corrosive byproducts such as HF. Consequently, the surfaces in contact with the melted polymer should be made of corrosionresistant alloys (Ebnesajjad and Fluoroplastics, 2015). Third, the extremely rapid crystallization and relaxation process of PCTFE brings great challenges for controllable adjustment of the molecular structure of PCTFE. In other words, in contrast to traditional polyolefins, the melting processing of PCTFE has stringent requirements to the processing machines. Based on these, exploring new processing techniques for PCTFE is promising. Besides, it is noticed that the co-monomer may

\section{REFERENCES}

Ameduri, B. (2009). From Vinylidene Fluoride (VDF) to the Applications of VDFContaining Polymers and Copolymers: Recent Developments and Future Trends. Chem. Rev. 109 (12), 6632-6686. doi:10.1021/cr800187m

Ameduri, B., and Sawada, H. (2016). Fluorinated Polymers: Volume 2: Applications. Royal Society of Chemistry, 18-26. chapter 1.

Boschet, F., and Ameduri, B. (2014). (Co)polymers of Chlorotrifluoroethylene: Synthesis, Properties, and Applications. Chem. Rev. 114 (2), 927-980. doi:10. $1021 / \mathrm{cr} 2002933$ bring complementary properties, leading to variable versatile CTFE-based copolymers. Therefore, a growing interest to apply CTFE-based materials to energy applications such as in piezoelectric and electrostrictive devices, fuel cell membranes, and photovoltaic has emerged. Although probably many other novel challenges exist, it can be expected that such areas will be further explored and should greatly attract the interest of industrial and academic researchers.

\section{AUTHOR CONTRIBUTIONS}

JZ wrote the first draft of the article. All authors contributed to conception and design of this review and also contributed to article revision, read, and approved the submitted version.

\section{ACKNOWLEDGMENTS}

The authors would like to thank Ms. Jing Yang, Ms. Wenhua Cheng, Mr. Tianyang Fan, and Mr. Sen Li for their kind assistance in preparing this article.

Boutevin, B., Cersosimo, F., and Youssef, B. (1992). Studies of the Alternating Copolymerization of Vinyl Ethers with Chlorotrifluoroethylene. Macromolecules 25 (11), 2842-2846. doi:10.1021/ma00037a009

Brown, E. N., Rae, P. J., and Orler, E. B. (2006). The Influence of Temperature and Strain Rate on the Constitutive and Damage Responses of Polychlorotrifluoroethylene (PCTFE, Kel-F 81). Polymer 47 (21), 7506-7518. doi:10.1016/j.polymer.2006.08.032

Carnevale, D., Wormald, P., Ameduri, B., Tayouo, R., and Ashbrook, S. E. (2009). Multinuclear Magnetic Resonance and DFT Studies of the Poly(chlorotrifluoroethylene-Alt-Ethyl Vinyl Ether) Copolymers. Macromolecules 42 (15), 5652-5659. doi:10.1021/ma900789t 
Dhanumalayan, E., and Joshi, G. M. (2018). Performance Properties and Applications of Polytetrafluoroethylene (PTFE)-a Review. Adv. Compos. Hybrid Mater. 1 (2), 247-268. doi:10.1007/s42114-018-0023-8

Dias, A. J., and McCarthy, T. J. (1987). Introduction of Carboxylic Acid, Aldehyde, and Alcohol Functional Groups onto the Surface of Poly(chlorotrifluoroethylene). Macromolecules 20 (9), 2068-2076. doi:10. 1021/ma00175a005

Drobny, J. G. (2020). "Applications of Fluoropolymer Films: Properties, Processing, and Products," in Safety, Hygiene, Disposal, Recycling of Fluoropolymer Films (William Andrew), 139-143. chapter 8. doi:10.1016/ b978-0-12-816128-9.00008-8

Ebnesajjad, S., and Fluoroplastics (2015). Non-processible Fluoropolymers-The Definitive User's Guide and Data Book. William Andrew 1, 300-306.

Feng, N., Mao, W. W., Gu, Y., Wang, A. S., and Tang, Y. W. (2015). Structure and Properties of Polychlorotrifluoroethylene Blends Toughened with Different Modifiers. Mod. Plastics Process. Appl. 27 (03), 11-14.

Feng, N., Yu, G. J., Li, W. S., Wang, J., and Sun, S. G. (2014). Effect of Rare Earth Compound Stabilizer on Polychlorotrifluoroethylene Materials. Plast. Sci. Tech. 42 (06), 109-112.

Gardiner, J. (2015). Fluoropolymers: Origin, Production, and Industrial and Commercial Applications. Aust. J. Chem. 68 (1), 13-22. doi:10.1071/ ch14165

Gee, R. H., Fried, L. E., and Cook, R. C. (2001). Structure of Chlorotrifluoroethylene/Vinylidene Fluoride Random Copolymers and Homopolymers by Molecular Dynamics Simulations. Macromolecules 34 (9), 3050-3059. doi:10.1021/ma001077a

Giannetti, E. (2001). Semi-crystalline Fluorinated Polymers. Polym. Int. 50 (1), 10-26. doi:10.1002/1097-0126(200101)50:1<10:aid-pi614>3.0.co;2-w

Hara, T. (1967). Dielectric Properties of Low Molecular Weight Polychlorotrifluoroethylene. Jpn. J. Appl. Phys. 6 (2), 135-146. doi:10.1143/ jjap.6.135

Hoffman, J. D., and Weeks, J. J. (1962). Rate of Spherulitic Crystallization with Chain Folds in Polychlorotrifluoroethylene. J. Chem. Phys. 37 (8), 1723-1741. doi:10.1063/1.1733363

Hoffman, J. D., Williams, G., and Passaglia, E. (1966). Analysis of the $\alpha, \beta$, and $\gamma$ Relaxations in Polychlorotrifluoroethylene and Polyethylene: Dielectric and Mechanical Properties. J. Polym. Sci. C: Polym. Symposia 14 (1), 173-235.

Ishigure, K., Tabata, Y., and Oshima, K. (1973). 19F Nuclear Magnetic Resonance Spectra of Tetrafluoroethylene-Propylene Copolymers. Macromolecules 6 (4), 584-588. doi:10.1021/ma60034a023

Ishigure, K., Tabata, Y., and Oshima, K. (1970). Nuclear Magnetic Resonance Spectra of a Isobutylene-Chlorotrifluoroethylene Copolymer. Macromolecules 3 (1), 27-29. doi:10.1021/ma60013a007

John, B., and Sandra, L. (2005). Blister Package. US20050077202A1.

Karkhanechi, H., Rajabzadeh, S., Di Nicolò, E., Usuda, H., Shaikh, A. R., and Matsuyama, H. (2016). Preparation and Characterization of ECTFE Hollow Fiber Membranes via Thermally Induced Phase Separation (TIPS). Polymer 97, 515-524. doi:10.1016/j.polymer.2016.05.067

Kawakami, S., Okamoto, T., Miyazaki, N., Uchino, B., Nomura, K., and Kato, H. (1996). Composition for an Aqueous Coating Material. US5548019A.

Khanna, Y. P., and Kumar, R. (1991). The Glass Transition and Molecular Motions of Poly(chlorotrifluoroethylene). Polymer 32 (11), 2010-2013. doi:10.1016/ 0032-3861(91)90166-g

Koti Reddy, C., Shekharam, T., and Shailaja, D. (2012). Preparation and Characterization of Poly(chlorotrifluoroethylene-Co-Ethylvinyl Ether)/ poly(styrene Acrylate) Core-Shells and $\mathrm{SiO} 2$ Nanocomposite Films via a Solution Mixing Method. J. Appl. Polym. Sci. 126 (5), 1709-1713. doi:10. 1002/app.36777

Lazár, M. (1958). Influence of the Solvent on the Polymerization Velocity of Trifluorochloroethylene. J. Polym. Sci. 29 (120), 573-578.

Li, J., Feng, N., Zhang, G. X., Qu, M. J., Wang, X. H., and Yu, G. J. (2015). Performance and Crystallization Behavior of PCTFE Toughened by Core-Shell ACR. China Synth. Resin Plastics 32 (03), 40-43.

Ma, Z. Y., and Li, W. S. (2005). Properties and Application of Polychlorotrifluoroethylene. Organo-Fluorine Industry 04, 11-12+18. doi:10. 1016/b978-1-4557-3199-2.00019-7

Mabry, J. M., Vij, A., Viers, B. D., Grabow, W. W., Marchant, D., Iacono, S. T., et al. (2007). Hydrophobic Silsesquioxane Nanoparticles and Nanocomposite
Surfaces. Sci. Tech. Silicones Silicone-Modified Mater. 964, 290-300. doi:10. 1021/bk-2007-0964.ch018

McKeen, L. W. (2015). Fluorinated Coatings and Finishes Handbook: The Definitive User's Guide. William Andrew, 384-410.

Mencik, Z. (1973). Crystal Structure of Polychlorotrifluoroethylene. J. Polym. Sci. A-2 Polym. Phys. 11 (8), 1585-1599. doi:10.1002/pol.1973.180110808

Okubo, M., Tahara, M., Saeki, N., and Yamamoto, T. (2008). Surface Modification of Fluorocarbon Polymer Films for Improved Adhesion Using AtmosphericPressure Nonthermal Plasma Graft-Polymerization. Thin Solid Films 516 (19), 6592-6597. doi:10.1016/j.tsf.2007.11.033

Price, F. P. (1952). The Development of Crystallinity in Polychlorotrifluoroethylene. J. Am. Chem. Soc. 74 (2), 311-318. doi:10.1021/ ja01122a006

Ramaswamy, S., Greenberg, A. R., and Krantz, W. B. (2002). Fabrication of Poly (ECTFE) Membranes via Thermally Induced Phase Separation. J. Membr. Sci. 210 (1), 175-180. doi:10.1016/s0376-7388(02)00383-6

Reddy, C. K., Raju, L. Y., Srinivas, P. V. S. S., Rao, P. S., Shekharam, T., and Shailaja, D. (2011). Preparation and Characterization of Core-Shell Nanoparticles Containing Poly(chlorotrifluoroethylene-Co-Ethylvinylether) as Core. J. Appl. Polym. Sci. 122 (3), 1807-1814. doi:10.1002/app.34262

Reimschuesel, H. K., Marti, J., and Murthy, N. S. (1988). Ethylenechlorotrifluoroethylene Copolymers. II. Effects of Structure on Resistance to thermal Stress Cracking. J. Polym. Sci. A. Polym. Chem. 26 (1), 43-59. doi:10. 1002/pola. 1988.080260105

Scott, A. H., Scheiber, D. J., Curtis, A. J., Lauritzen, J. I., and Hoffman, J. D. (1962). Dielectric Properties of Semicrystalline Polychlorotrifluoroethylene. J. Res. Natl. Bur. Stan. Sect. A. 66A (4), 269-+. doi:10.6028/jres.066a.028

Shen, J. B., Guo, S. Y., and Xu, R. Y. (2021). A Method for Improving the Processability and Toughness of Polychlorotrifluoroethylene, CN112552624A.

Shen, J. B., Xu, R. Y., and Guo, S. Y. (2021). A Method for Fabricating Low Dielectric Loss, High Transparency and Excellent Water Resistance Membranes, CN111961298A.

Shu, J. Z., Deng, Y., Peng, R. K., Yang, Z. Y., Zhao, M. C., and Sun, J. H. (1986). Study on Chain Structure of Vinylidene Fluoride-Trifluorochloroethylene Copolymer. Chin. J. Org. Chem. 03, 187-194.

Siergiej, R. W., and Danielson, N. D. (1983). Phenyl-modified Kel-F as a Column Packing for Liquid Chromatography. Anal. Chem. 55 (1), 17-22. doi:10.1021/ ac00252a008

Simone, S., Figoli, A., Santoro, S., Galiano, F., Alfadul, S. M., Al-Harbi, O. A., et al. (2012). Preparation and Characterization of ECTFE Solvent Resistant Membranes and Their Application in Pervaporation of Toluene/water Mixtures. Sep. Purif. Tech. 90, 147-161. doi:10.1016/j.seppur.2012.02.022

Song, H. L., Han, A. C., Zhang, Y., Chen, R., Li, J., and Guo, S. Y. (2018). Effects of Crystalline Morphology on the High-Frequency Dielectric Properties of Poly(chlorotrifluoroethylene). Polym. Mater. Sci. Eng. 34 (06), 49-53.

Song, J., Zhang, C. J., and Zhang, W. L. (2013). Progress on Research of Polychlorotrifluoroethylene. Zhejiang Chem. Industry 44 (03), 1-4.

Sun, B., Chen, K., Zhang, W. L., and Gao, Z. H. (2019). Progress of Chlorotrifluoroethylene Copolymer and Application. New Chem. Mater. 47 (10), 27-32.

Tabata, Y., Ishigure, K., Higaki, H., and Oshima, K. (1970). Radiation-Induced Copolymerization of Fluorine-Containing Monomers. J. Macromolecular Sci. A - Chem. 4 (4), 801-813. doi:10.1080/00222337008060982

Tatsuno, H., Aimi, K., and Ando, S. (2007). Solid-state19F MAS NMR Study on the Conformation and Molecular Mobility of Poly(chlorotrifluoroethylene). Magn. Reson. Chem. 45 (5), 401-409. doi:10.1002/mrc.1982

Teng, H. (2012). Overview of the Development of the Fluoropolymer Industry. Appl. Sci. 2 (2), 496-512. doi:10.3390/app2020496

Thomas, W. M., and O'Shaughnessy, M. T. (1953). Kinetics of Chlorotrifluoroethylene Polymerization. J. Polym. Sci. 11 (5), 455-470. doi:10.1002/pol.1953.120110508

Tomkovic, T., and Hatzikiriakos, S. G. (2020). Rheology and Processing of Polytetrafluoroethylene ( PTFE ) Paste. Can. J. Chem. Eng. 98 (9), 1852-1865. doi:10.1002/cjce.23816

Ursino, C., Simone, S., Donato, L., Santoro, S., De Santo, M. P., Di Nicolò, E., et al. (2016). ECTFE Membranes Produced by Non-toxic Diluents for Organic Solvent Filtration Separation. RSC Adv. 6 (84), 81001-81012. doi:10.1039/ c6ra13343f 
Vecellio, M. (2000). Opportunities and Developments in Fluoropolymeric Coatings. Prog. Org. Coat. 40 (1), 225-242. doi:10.1016/s0300-9440(00) 00153-3

Wang, L., Liu, C., Shen, S., Xu, M., and Liu, X. (2020). Low Dielectric Constant Polymers for High Speed Communication Network. Adv. Ind. Eng. Polym. Res. 3 (4), 138-148. doi:10.1016/j.aiepr.2020.10.001

Wang, W. G., Yang, Y., and Chen, B. N. (2007). Studies of EthyleneChlorofluoroethylene Copolymers. Organo-Fluorine Industry 02, 28-32.

Wang, X. X., Cao, W. Q., Cao, M. S., and Yuan, J. (2020). Assembling NanoMicroarchitecture for Electromagnetic Absorbers and Smart Devices. Adv. Mater. 32 (36), 2002112. doi:10.1002/adma.202002112

Wei, C. P., and Shi, T. (1995). Studies on Reinforced Polychlorotrifluoroethylene. Organo-Fluorine Industry 01, 1-3.

Wen, J. L., Qu, Y. W., Cui, Y., Zhang, C. M., and Zhang, L. M. (2018). Processing Technology of CF Reinforced Polychlorotrifluoroethylene Composite. Eng. Plastics Appl. 46 (01), 58-61+69.

Wu, L., Zhang, D. S., Hu, W., Li, W. Y., Chen, H., Sun, X. H., et al. (2015). Monocyclic Carboxylate Nucleating Agent Modified Polychlorotrifluoroethylene, CN104693649A.

Xu, K., Cai, Y., Hassankiadeh, N. T., Cheng, Y., Li, X., Wang, X., et al. (2019). ECTFE Membrane Fabrication via TIPS Method Using ATBC Diluent for Vacuum Membrane Distillation. Desalination 456, 13-22. doi:10.1016/j.desal. 2019.01.004

Xu, R. Y., Shen, J. B., and Guo, S. Y. (2020). Research Progress in the Preparation, Modification, and Processing Application of Polychlorotrifluoroethylene. Organo-Fluorine Industry 02, 18-24.

Yavari, M., Okamoto, Y., and Lin, H. (2018). The Role of Halogens in Polychlorotrifluoroethylene (PCTFE) in Membrane Gas Separations. J. Membr. Sci. 548, 380-389. doi:10.1016/j.memsci.2017.11.043

Zhang, X. H., and Zhou, J. Y. (2017). Study on Low Temperature Performance of Ultra-low Temperature Valves with PCTFE Gasket. Chem. Eng. Machinery 44 (05), 497-501.
Zhang, Y., Liu, Z., Zhang, X., and Guo, S. (2021). Sandwich-layered Dielectric Film with Intrinsically Excellent Adhesion, Low Dielectric Constant, and Ultralow Dielectric Loss for a High-Frequency Flexible Printed Circuit. Ind. Eng. Chem. Res. 60 (31), 11749-11759. doi:10.1021/acs.iecr.1c01676

Zhao, X. Y., and Liu, H. J. (2010). Review of Polymer Materials with Low Dielectric Constant. Polym. Int. 59 (5), 597-606. doi:10.1002/pi.2809

Zulfiqar, S., Rizvi, M., Munir, A., Ghaffar, A., and McNeill, I. C. (1996). Thermal Degradation Studies of Copolymers of Chlorotrifluoroethylene and Methyl Methacrylate. Polym. Degrad. Stab. 52 (3), 341-348. doi:10.1016/0141-3910(95) 00241-3

Zulfiqar, S., Zulfiqar, M., Rizvi, M., Munir, A., and McNeill, I. C. (1994). Study of the thermal Degradation of Polychlorotrifluoroethylene, Poly(vinylidene Fluoride) and Copolymers of Chlorotrifluoroethylene and Vinylidene Fluoride. Polym. Degrad. Stab. 43 (3), 423-430. doi:10.1016/0141-3910(94) 90015-9

Conflict of Interest: JZ, MZ, MH, DZ, and YD are employed by China Electronics Technology Group Corporation.

Publisher's Note: All claims expressed in this article are solely those of the authors and do not necessarily represent those of their affiliated organizations, or those of the publisher, the editors, and the reviewers. Any product that may be evaluated in this article, or claim that may be made by its manufacturer, is not guaranteed or endorsed by the publisher.

Copyright (c) 2022 Zou, Zhang, Huang, Zhao and Dai. This is an open-access article distributed under the terms of the Creative Commons Attribution License (CC BY). The use, distribution or reproduction in other forums is permitted, provided the original author(s) and the copyright owner(s) are credited and that the original publication in this journal is cited, in accordance with accepted academic practice. No use, distribution or reproduction is permitted which does not comply with these terms. 